\title{
A cognição em questão: invenção, aprendizagem e Educação Matemática
}

\section{A study on cognition: invention, learning and Mathematical Instruction}

\author{
Giovani Cammarota* \\ Sônia Maria Clareto**
}

Resumo: Este artigo propõe uma interlocução entre a noção de invenção e a Educação Matemática, em particular, a sala de aula de matemática. A discussão tem como mote um episódio de pesquisa de campo, realizada a partir do método cartográfico em uma escola da rede pública de Juiz de Fora/MG. Em torno deste episódio são articulados dois discursos acerca da cognição e da aprendizagem: o da Teoria dos Campos Conceituais, de Gérard Vergnaud, e o do Modelo dos Campos Semânticos, de Rômulo Lins. A invenção opera transversalmente nos dois discursos, abrindo possibilidades de pensar a aprendizagem como coprodução si-mundo.

Palavras-chave: Cognição inventiva. Modelos de aprendizagem. Sala de aula de matemática.

Abstract: This paper proposes a dialogue between the notion of invention and
mathematical instruction, mainly, the mathematics classroom. The discussion is based
upon an episode of field research, carried out in the Cartography method in a public
school in Juiz de Fora/MG. Around this episode, two discourses are articulated about
cognition and learning: the Conceptual Field Theory, by Gérard Vergnaud, and
the Semantic Field Model, by Rômulo Lins. The invention crosses both discourses
transversally, creating possibilities of thinking learning as a co-production of self-world. Keywords: Inventive cognition. Learning models. Mathematics classroom.

\section{Que caminhos?}

Neste artigo, propomos uma interlocução entre a noção de invenção e a Educação Matemática. Mais comumente, a área da Educação Matemática vem colocando a questão da aprendizagem matemática por meio de uma representação em sentido forte, na acepção de uma imagem universal do pensamento. Assim,

\footnotetext{
* Professor da Universidade Federal de Juiz de Fora. Mestrando do PPGE/UFJF. E-mail: < giomatufff@ yahoo.com.br>

** Professora da Universidade Federal de Juiz de Fora. Docente do PPGE/UFJF. E-mail: <sclareto@ yahoo.com.br>
} 
por mais que se considere que exista uma diversidade de modos de pensar, esses modos levam a produtos necessários dados de antemão pela matemática. $\mathrm{Na}$ interlocução com Gilles Deleuze e Virgínia Kastrup, propomos colocar o problema da cognição e da aprendizagem matemática não em termos de diversidade de modos de pensar, mas como instauração da diferença no pensamento.

A pesquisa na qual se enreda este artigo tem como principal objetivo problematizar modos pelos quais a cognição tem sido "praticada" na Educação Matemática. O termo problematização é pensado junto a Deleuze (2006), em desdobramentos oferecidos por Kastrup (2007), caracterizando-se não por perguntar pela eficácia, mas por direcionar a interrogação para sua constituição e seus efeitos. Então, não perguntaremos pela eficácia da noção de cognição praticada pela e na Educação Matemática; ou seja, não perguntaremos se os discursos acerca da aprendizagem matemática funcionam ou não, ou quais seriam seus limites. Aos discursos não cabe a pergunta da eficácia: os discursos “funcionam”. Não focaremos, tampouco, em uma avaliação da verdade destes discursos, ou seja, qual deles é mais verdadeiro. De certa maneira, trata-se de questionar como um objeto, discurso ou forma se tornou o que é. A centralidade fica em como a cognição, constituindo um certo modo de produzir problemas - problematizar - acaba por circunscrever possibilidades de construir o mundo. Por isso, ao problematizar, não se está colocando em xeque a legitimidade dos estudos em torno de um dado objeto, mas perguntando por sua constituição e por seus efeitos.

Em nossa pesquisa procuramos problematizar a cognição em seus modos de operar na Educação Matemática e perguntar pelos efeitos de tal problematização, quando pensamos a aprendizagem e a sala de aula de matemática.

Entre os diferentes modos que a Educação Matemática vem perspectivando a cognição, nos ocuparemos, no âmbito deste artigo, com a Teoria dos Campos Conceituais, de Gérard Vergnaud, e o Modelo dos Campos Semânticos, de Rômulo Lins. Tais perspectivas, talvez as mais presentes na área, colocam de modos distintos o problema da cognição e suas relações com a aprendizagem. Resta perguntar, portanto, pela constituição de cada uma dessas teorias e pelas implicações éticas e políticas dos modos como colocam o problema da cognição e da aprendizagem.

O presente texto procura pensar o problema da cognição e da aprendizagem da matemática na sala de aula, junto a um evento da pesquisa de campo em curso na investigação na qual este artigo se enreda ${ }^{1}$. Para tanto, iniciaremos por uma discussão mais apurada do que entendemos por invenção, situando nossa

\footnotetext{
${ }^{1}$ Nossa pesquisa, além do estudo indicado, realiza uma investigação de campo em uma escola da Rede Municipal de Ensino de Juiz de Fora/MG com o objetivo de investigar como a noção de cognição inventiva traz elementos para discutirmos a sala de aula de matemática.
} 
problemática em termos éticos e políticos. Na sequência, situaremos a cartografia como método de pesquisa potente para a investigação da sala de aula de matemática. Nessa seção apresentaremos, ainda, o evento da pesquisa de campo que deu corpo às nossas discussões sobre cognição e Educação Matemática. A partir desse evento, dois discursos entram em cena: o primeiro é o discurso da Teoria dos Campos Conceituais, e o segundo é o do Modelo dos Campos Semânticos. A invenção aparece transversalmente, problematizando os dois discursos que se constituem. Por fim, nas considerações finais, examinaremos potencialidades da noção de cognição inventiva para se pensar a sala de aula de matemática.

\section{Por que invenção?}

A questão apontada no título da presente seção pode constituir-se em uma armadilha: em que parâmetros colocar a justificativa da opção pela invenção? Pretendemos colocar a questão da invenção em parâmetros distintos das aspirações psicologizantes e cognitivistas da individualização de um sujeito que inventa, para além do apelo de verdade que a noção de invenção parece exercer socialmente - invenção é bom em si, inventar é desejável. O que pretendemos se distancia de uma dimensão axiológica que julga e separa o que é bem do que é mal, uma dimensão moralizante do conhecimento, enfim, agindo como num impulso em direção à verdade, uma vontade de verdade, como diria Nietzsche (1886/1992, 1882/2001a, 1887/2001b). Como escapar a essa armadilha?

Parece que estamos em uma condição de investigação que resvala na possibilidade de constituição de um discurso, para além e aquém, da verdade. Camargo (2008), ao discutir o conceito de verdade em Nietzsche, coloca a questão: "Como Nietzsche pode pretender criticar os discursos de verdade sem que ele mesmo não pretenda que seu discurso seja tido como tal?" (CAMARGO, 2008, p. 102). Esta questão nos inspira a pensar nosso problema: como justificar a invenção sem constituir um discurso que se pretenda "a verdade" sobre a cognição e sobre a aprendizagem na Educação Matemática. Continuando a pensar com Camargo (2008), uma pista se apresenta:

Até agora a verdade foi o valor máximo que um discurso podia alcançar. Neste ponto, tornava-se inquestionável. Até que outro discurso o negasse e em seu lugar apresentasse outra verdade, esta sim, a verdade, que desbancaria a anterior. E assim sucessivamente, como se enganos estivessem sendo corrigidos por uma suposta evolução do pensamento. Neste enredo, Nietzsche seria apenas mais um a apresentar uma nova verdade a ser superada no futuro. Mas o discurso de Nietzsche critica, justamente, esta estrutura e estaria sendo inconsistente se apresentasse sua própria perspectiva como a única possível e verdadeira. Como faz Nietzsche, então, para sustentar sua argumentação contra os discursos filosóficos sobre a verdade, sem pretender, com isto, 
apresentar uma nova verdade? E como acreditar em seu discurso se, de antemão, já sabemos que não é verdadeiro? - Estas questões, bastante legítimas, não são deixadas sem resposta pelo filósofo. Elas podem ser pensadas a partir dos seguintes questionamentos: É possivel pensar o valor de um discurso sem referi-lo à verdade? Será que um discurso parcial e perspectivo daria conta daquilo que a filosofia tem a dizer? (CAMARGO, 2008, p. 102-103, grifo nosso).

Queremos dizer que não se trata de "um movimento de superação": um modelo de cognição superando outro. Nossa intenção não é a de construir um "modelo cognitivo inventivo". Se assim o fosse, na tentativa de negar um modelo representacional de cognição em favor de outro, um modelo inventivo, descaracterizaríamos a proposição da inventividade, já que ela se submeteria a um modelo.

Pensando com Camargo (2008), roubamos $^{2}$ a questão, que grifamos na citação acima, para o nosso problema. É possível pensar o valor de nosso discurso sem referi-lo à verdade? Ou seja, é possível justificar a colocação do problema da invenção na Educação Matemática sem produzir um discurso que se paute na e pela verdade? A resposta de Nietzsche igualmente nos ajuda: o conhecimento não se refere à verdade, mas ao sentido e ao valor. O ponto central, então, não é mais moral - a verdade como uma imagem moral do conhecimento, definindo o bem e o mal, o verdadeiro e o falso - mas ética - trazendo as implicações e os efeitos, o valor e o sentido. A questão do conhecimento, então, desloca-se de "qual discurso é mais verdadeiro?" para "em que esse discurso implica? A serviço de que tipo de existência está este discurso?”. Atrelado à ética, aparece, também, uma dimensão política: que tipo de relação se estabelece com o conhecimento? Que tipo de relação se estabelece com a aprendizagem? Estas questões evidenciam mais o conhecer que o conhecimento. Ou seja, o conhecer referindo-se a uma atitude, portando, assim, uma dimensão política: política cognitiva. Quer dizer: o problema da cognição não é um problema somente teórico, mas fundamentalmente um problema político. Enquanto o modelo da representação pressupõe a existência prévia do sujeito cognoscente e do objeto que se dá a conhecer, propor a indissociabilidade sujeito e objeto, si e mundo, implica um convite para se existir de um tal modo a aceitar o mundo como efeito de nossa prática cognitiva (KASTRUP; TEDESCO; PASSOS, 2008). Que políticas cognitivas se configuram na relação do conhecer?

A filosofia moderna - de Descartes a Kant - instituiu como figuras centrais das relações de conhecimento as categorias de sujeito e objeto. A crença na universalidade do conhecimento, garantido pelo senso comum, que institui a

\footnotetext{
${ }^{2}$ Estamos usando o termo no mesmo sentido do que aquele dado por Deleuze e Guattari (1997). Para eles, não existem cópias, sobreposições perfeitas de ideias. O que existem são os roubos: roubos criativos.
} 
forma do Mesmo, e pela partilha do bom senso, que institui a natureza reta do pensamento, tem por efeito pensá-lo enquanto um estado de coisas e não enquanto um processo. Sujeito e objeto são identidades, zonas ontológicas distintas que, em existindo, entram em relação. Nesse contexto, conhecer é representar, por meio do uso concordante das faculdades sobre um objeto suposto como o mesmo. (DELEUZE, 2006). É nisso que a filosofia moderna implica: em conhecimento entendido como reconhecimento do mesmo, como inclinação reta do pensamento, como vontade de verdade. Nesse sentido, a diferença é pensada sob a égide do diferente, como uma diferença que se subsume à identidade.

O diálogo de nosso trabalho com filósofos como Nietzsche, Deleuze e Foucault acaba por produzir uma vontade de outra coisa, de pensar a diferença em si, não submetida à identidade. Colocamos em questão, assim, o valor da verdade moderna. A pergunta que resta, em função de nossa problemática, é, então: que cognição e aprendizagem matemática a diferença produz? É no bojo dessa questão que a noção de invenção surge como intercessora.

O trabalho de Kastrup (2007) parte de duas afirmações: a inexistência de uma psicologia da invenção nos estudos da cognição e a necessidade da exploração das condições de sua formulação. Para a autora, a inexistência de um estudo da invenção se deu por um certo modo de colocar o problema da cognição que parte do suposto de que o conhecimento é representação. A cognição é, portanto, recognição e se define como um uso concordante das faculdades de entendimento direcionada a um determinado objeto suposto como sempre o mesmo (DELEUZE, 2006). A suposição do objeto como mesmo funda uma Imagem Dogmática do Pensamento à qual tudo o que é representação se refere. Dessa maneira, as questões levantadas pela psicologia cognitiva são as das condições e do funcionamento da recognição. Quando partimos da caracterização da recognição, aprender é constituir uma representação para o mundo. Submetida, assim, a uma Imagem Dogmática do Pensamento, a aprendizagem é algo de caráter previsível e pode, portanto, ser modelada. A política cognitiva praticada nesse contexto é a política de recognição.

Por outro lado, ao explorar as condições de uma psicologia da invenção, Kastrup (2007) vai propor uma noção de aprendizagem como coengendramento de si e do mundo. Entendida dessa maneira, a aprendizagem deixa de pressupor sujeito e objeto como polos a partir dos quais a cognição opera para considerá-los estabilizações provisórias da ação cognitiva portadoras de uma inventividade intrínseca. É, assim, portanto, que sujeito e objeto são tirados de seu lugar de condição da cognição para serem pensados como efeitos provisórios dela. Aprendizagem como invenção de si e do mundo. É interessante ressaltar que a noção de invenção opera uma ampliação do conceito de cognição, ou seja, a invenção não é refratária à representação, mas opera nela uma torção 
fundamental: longe de estabelecer imagens universais e dogmáticas do pensamento, a invenção produz representações pragmáticas (VARELA, [199-]). Por isso, a invenção não é o contrário da representação, mas guarda uma relação de constituição e diferenciação com ela.

\section{Assumindo a cartografia como procedimento de pesquisa: uma sala-de-aula-de-matemática?}

Produzir dados de campo é uma preocupação central da cartografia. Como se produz algo que já estava em campo, um dado? Kastrup (2009) nos ajuda a pensar tal questão apontando que a expressão "produção de dados" tem por efeito demarcar o espaço de produção de algo que já estava em campo, em alguma medida, de maneira implícita, de modo virtual. A produção dos dados, portanto, atualiza virtualidades. É importante ressaltar, porém, que as virtualidades do campo são atualizadas segundo um movimento de diferenciação e de invenção, e não de captação do possível. Quer dizer, a invenção opera pela problematização das formas constituídas. O que significa dizer que a invenção se dá a partir de uma matéria bruta, na "materialidade" das formas e dos objetos. Não se inventa do nada, mas a partir de um "subtrato" material, com as forças sem estabilidade permanente. As virtualidades se atualizam num movimento inventivo e, por isso, num coengendramento si-mundo. Trata-se de dar voz aos fluxos de forças presentes no campo de pesquisa. Enquanto que captar o possível é representá-lo como tal, a atualização de virtualidades não implica resultados necessários e previsíveis, mas atualizações de virtualidade sempre novidadeiras.

A cartografia não se coloca como um método interpretativo, mas sim como um método que se faz caso a caso e que tem por característica o estudo de forças em agenciamentos, de pistas de processualidades em movimento. Nesse sentido é um método que descreve um campo perceptivo e o analisa já que busca compreender os efeitos daquela configuração provisória de forças no campo, que subjetividades e mundos produz (KASTRUP, 2009).

Pensemos em uma sala de aula de matemática: poderíamos pensá-la, escrevê-la como um objeto que circunscreve algumas variáveis: a relação professor-aluno, os processos de ensino-aprendizagem, incluídas aí as variáveis didático-metodológicas. Essa é uma sala de aula que todo o educador matemático conhece, pois corresponde a uma imagem do que pensamos que seja a sala de aula. O que a cartografia acaba por nos apontar é que os modos pelos quais as relações se estabelecem no campo de pesquisa são sempre singulares. Em nossa sala de aula estão presentes os elementos relação professor-aluno, conteúdo matemático, estratégias didático-metodológicas. Mas todos esses objetos são, já, formas. Foram constituídos em algum momento. Importa-nos perguntar pelo 
constituinte das formas. E no caso da escola na qual estamos realizando nossa pesquisa, podemos falar dos mais diversos discursos que dizem desta sala de aula: o discurso do projeto político-pedagógico, dos projetos extraclasse que têm por objetivo minimizar o problema do fracasso escolar, conversa sobre como as brigas de gangue do bairro adentram o ambiente escolar, conversa de alunos sobre a matemática etc. A cartografia aparece como método, portanto, por uma exigência do objeto de pesquisa. Uma sala de aula de matemática é produzida, é inventada com todos os efeitos que ela dispara: subjetividades, aprendizagens, modos de estabelecer relações de conhecimento, matemática, entre outros. Tal produção não tem sede no pesquisador como invenção de um sujeito, pois se apoia num substrato material dos acontecimentos daquela sala. Ao mesmo tempo, a sala de aula de matemática não é prévia ao processo de pesquisa, não é um objeto externo que informa coisas ao pesquisador e que pode ser, portanto, representada. A sala de aula de matemática se inventa no entre, na relação de conhecimento que tem por efeito a produção do pesquisador e de si própria. Suas singularidades são afirmadas nesse processo. É nesse sentido que podemos dizer que a cartografia envolve um rigor e uma postura política do pesquisador, que deve ter atenção para não incorrer nos modos objetivista e subjetivista de pesquisar. Vale aqui a lembrança de que o paradigma do cartógrafo "não é o do conhecer, mas o do cuidar, não sendo também o do conhecer para cuidar, mas o do cuidar como a única forma de conhecer, ou ainda, o paradigma da inseparabilidade imediata entre cuidar e conhecer" (PASSOS; EIRADO, 2009, p. 122). É preciso, assim, um ethos do cuidado com a pesquisa que se pratica a todo o instante e que garanta um rigor da cartografia.

Ter como campo de pesquisa uma sala de aula de matemática, portanto, além de comportar tal atitude por parte do pesquisador, implica entendê-la como um coletivo de forças, ou seja, um espaço que se produz num movimento de metaestabilidade ${ }^{3}$. Nesse sentido, nosso campo é composto por duas facetas, a do instituído e a do movente. Enquanto a primeira tende à estabilidade e ao reconhecimento da sala de aula, na segunda, um instituinte subjaz ao instituído como uma franja de pré-individualidade, ou seja, como potência de diferenciação da sala de aula em formações outras que estão sempre se fazendo. É, enfim, pensá-la como sala-de-aula-de-matemática (CAMMAROTA; CLARETO; SILVA, 2011).

\footnotetext{
${ }^{3}$ A metaestabilidade é ligada à individuação das formas. Considera-se que toda a forma comporta em si duas tendências. Uma dela é a tendência à repetição de si, à estabilidade das formas. Essa primeira dimensão da individuação é recognitiva, passível de ser representada. A outra é a dimensão pré-individual, marcada por diferenças puras que garantem a não cristalização das formas e mantém em curso o processo de individuação. Dessa maneira, não se poderia falar em um fenômeno de estabilidade do processo de individuação, já que a dimensão pré-individual garante um devir. Por outro lado, as tendências à repetição de si e à recognição garantem uma estabilidade provisória. Nesse sentido, falamos em uma metaestabilidade das formas individuadas.
} 
É daí que surge, então, a questão: todos sabem o que é uma escola? Todos sabem o que é uma sala-de-aula-de-matemática?

$$
* * *
$$

Entrar em sala de aula nunca é uma tarefa fácil. Como pesquisador, especialmente. Colocar em suspensão aquilo que já se espera que seja uma aula de matemática é um exercício que se pratica a todo o momento. Desnaturalizar um espaço desde muito babitado, como aluno, como professor é estar atento, à espreita, perguntando sempre o que acontece quando nada parece acontecer ${ }^{4}$.

Naquela manhã estamos na turma do $6^{a}$ ano $A$. Há 24 alunos presentes na aula. Estamos no segundo horário da professora naquela turma. No borário anterior ela bavia gastado pelo menos vinte minutos de seu tempo conversando com os alunos sobre um episódio de indisciplina que ocorrera no dia anterior. Howve um discurso com dedos indicadores apontados, cenhos franzidos, tons de voz acima do costume. Alunos e professora não se encaravam, os corpos quietos em suas carteiras, retesos. Os olhares baixos, cabeças abaixadas sobre as mesas. Para além de uma voz, nenbuma outra. A conversa surtira efeitos nos corpos. Produziu-se silêncio, movimentos contidos. A aula podia continuar.

Professora: Gente, como eu comparo números?

Não há resposta.

Professora: E como en comparo duas maçãs? - ela espera alguma resposta que não vem e, então, continua - Bom, eu posso comparar duas maçãs pela cor, não posso? Dižer que uma está mais vermelha que a outra? Ou pelo peso? Uma maşã está mais pesada que a outra. Ou pelo cheiro, pela textura, ou pelo tamanho. Existem vários meios de se comparar maçass, não é mesmo? - o silêncio começa a ser quebrado pelo assentimento de alguns.

A professora refaz, então, a pergunta inicial. Como se comparam dois números? E emenda:

Professora: Como en comparo 8 e 5 ?

Um aluno: Quando um é maior!

A professora assentiu, aguardou mais um pouco e mais dois alunos falam:

Outro aluno: 8 é par e 5 é impar.

Professora: Não é comparação, né?

Ainda outro aluno: Dividindo!

Professora: Dividindo? - o tom da professora pareceu desencorajar o menino que havia sugerido a divisão. Ela, então, virou-se para o quadro e escreven as frações $\frac{3}{4} e \frac{4}{6}$, dizendo Se eu comi quatro sextos de uma pizza e o Celso - e aponta para um menino no fundo da sala - comeu três quartos de uma pizza do mesmo tamanho, quem comeu mais?

\footnotetext{
${ }^{4}$ A questão "o que acontece quando nada parece acontecer?" é recorrente na cartografia.
} 
Alunos (vários, em coro): Você!

Diante da resposta, a professora desenhou dois círculos no quadro, cada qual representando uma das frações a que ela fazia referência. E refez a pergunta: quem comeu mais? Os alunos voltaram a dizer, em coro, que havia sido ela a comer mais.

Professora: Vou colorir esse desenho para vocês enxergarem melhor!

Após colorir os desenhos com giz no quadro, a professora refaz a pergunta aos alunos, que mudam sua reposta, apontando Celso como aquele que comera mais pizza.

Professora: Gente, pensa que é o aniversário de vocês. Daí sua mãe vai na padaria e compra um bolo para fazer uma festa para as pessoas que moram com você. Na sua casa moram você, seu pai, sua mãe e seus dois irmãos. Quanto cada um vai comer do bolo? - e faz. um círculo no quadro dividido em cinco partes.

Alunos (em coro): Um quinto!

Professora: Muito bem! - preenche um dos cinco espaços dentro do círculo - Agora imagina que você está na festa e de repente chega aquela sua tia com todos os seis filhos dela sem avisar. E aí, cada um vai comer mais ou menos bolo?

Alunos (em coro): Menos!

Professora: E quanto cada um vai comer? - ela faz outro círculo ao lado daquele, dividindo-o em doze partes.

Alunos (em coro): Um doze avos.

A professora assente com um movimento positivo de cabeça.

Professora: Você entende que isso é fração? Todo mundo come um pedaço igual.

Um aluno: Eu falava que a festa tinha acabado!

Outro aluno: Se bem que a gente não dá um pedaço igual para todo mundo. A gente não faz isso. Eu dou mais para quem gosto mais.

Enquanto isso, a professora escreve no quadro:

Comparação de frações

Como fazer?

Leitura da página 177

Copiar os quadros rosa do livro.

E o sinal anuncia o fim da aula. 


\section{Que discursos junto à sala de aula de matemática?}

Temos por objetivo apontar as diferenciações que acontecem no relato que aqui apresentamos junto a uma aula de matemática e que podem ser pensadas enquanto potência de invenção.

Dois discursos...

$$
* * *
$$

$1^{\circ}$ discurso: se tomarmos o exemplo das maçãs dado pela professora, poderíamos pensar que os alunos seguiram a mesma estratégia que ela. Elegeram um atributo dos inteiros 8 e 5 para fazerem a comparação. O segundo aluno tomou como base a distinção qualitativa dos inteiros em pares e ímpares, enquanto que o terceiro tomou por base a operação de divisão. Se pensarmos que os alunos estavam estudando frações e que a comparação entre 8 e 5 serviria como fundamento para que se discutisse a comparação entre racionais, poderíamos dizer que a distinção proposta pelo terceiro aluno comporta um viés quantitativo e qualitativo: qualitativo porque o quociente $8: 5=1,6$ permitiria dizer que $8>$ 5; quantitativo porque permitiria dizer quantas vezes 8 é maior que 5 .

Porém esse discurso está inserido nos estudos da epistemologia genética, para a qual a investigação acerca da aprendizagem depende do desenvolvimento das estruturas lógico-operatórias no âmbito do sujeito. Tais estruturas "correspondem, sob uma forma naturalmente muito elementar, senão rudimentar, [...] às coordenações necessárias ao funcionamento de toda a inteligência, desde os graus mais primitivos de sua formação" (PIAGET, 1979, p. 24-25). É, ainda, necessário salientar que a estrutura à qual nos referimos é um sistema de transformações que comporta leis enquanto sistema e tem três características principais: a totalidade, as transformações e a autorregulação (PIAGET, 1979). O desenvolvimento cognitivo é estrutural e, portanto, comporta todas essas características.

Resta, então, a questão de como os chamados construtivismos piagetianos podem ser pensados no âmbito da escola. Tendo essa preocupação, o psicólogo francês Gerard Vergnaud desenvolveu a Teoria dos Campos Conceituais, cuja questão central é a construção dos conceitos em sala de aula. O autor testou sua teoria com conceitos matemáticos, o que a fez ganhar espaço nas pesquisas em Educação Matemática.

Nesta teoria, a noção de conceito isolado acaba sendo substituída pela de campo conceitual, definido como um conjunto de situações para as quais existem uma gama de conceitos, procedimentos e representações simbólicas em estreita conexão (VERGNAUD, 1988). Assim, fala-se em campo conceitual de estrutura aditiva, de estrutura multiplicativa, de estrutura algébrica, fazendo-se referência, assim, ao conteúdo matemático de base. As estruturas aditivas, portanto, têm seu escopo circunscrito a operações de soma e subtração, por exemplo. 
Se voltarmos à situação de comparação entre 8 e 5, devemos ter em mente que a ação dos sujeitos é condicionada por conhecimentos-em-ação, ou seja, toda a ação cognitiva faz referência a um saber matemático formal, embora ele não esteja explicitado pelo aluno. Dessa maneira, as falas do primeiro e do terceiro alunos são mais adequadas à questão da comparação, pois são formas possíveis de se compararem números, segundo o saber matemático formal. A caracterização em par ou ímpar não diz da ordenação dos números 8 e 5 no conjunto dos racionais, mas a qualidades dos elementos do conjunto.

O primeiro aluno fez uso da noção de ordinalidade da sequência dos números naturais, o que era o procedimento mais simples para aquela situação, embora não fosse extensível para o caso seguinte da aula, que era a comparação entre frações.

Já a terceiro aluno faz uso de uma divisão entre 8 e 5, o que faz referência ao campo conceitual de estrutura multiplicativa e responde ao problema da ordenação de maneira indireta, já que depende da análise do resultado da divisão em termos do teorema da tricotomia ${ }^{5}$. Assim, se o quociente é menor que 1, temos que o dividendo é menor que o divisor; se o quociente é exatamente 1, o dividendo e o divisor são iguais; enquanto que se o quociente for maior que 1, o dividendo é menor que o divisor. Note-se que esta estratégia de comparação é extensível ao caso dos números fracionários.

$2^{\circ}$ discurso: podemos partir da fala da professora: Bom, eu posso comparar duas maçãs pela cor, não posso? Dizer que uma está mais vermelha que a outra? Ou pelo peso? Uma maçã está mais pesada que a outra. Ou pelo cheiro, pela textura, ou pelo tamanho. Existem vários meios de se comparar maçãs, não é mesmo?

Lembremos, agora, a fala dos três alunos frente à pergunta "como eu comparo 8 e 5?": "quando um é maior"; "8 é par e 5 é impar"; e "dividindo".

Uma primeira questão que aparece diz respeito à enunciação da professora. Quando, diante da ausência de qualquer resposta dos alunos, ela inicia uma explanação sobre comparações possíveis de serem feitas com maçãs, aparecem atributos como massa, cor, cheiro, tamanho, todos eles fortemente sensório-perceptivos. É interessante notar que coexistem diversas maneiras de comparar maçãs no exemplo dado pela professora: o procedimento é tomar como base de comparação um dos atributos possíveis para duas ou mais maçãs distintas.

No decorrer da situação, poderemos perceber que o discurso da professora acaba por legitimar a fala do primeiro aluno, à medida que o que ela efetivamente quer ensinar é: dados dois números racionais, como se distingue o maior

${ }^{5}$ Dados quaisquer dois reais $\mathrm{x}$ e $\mathrm{y}$ verifica-se, necessariamente, uma e só uma das condições: $\mathrm{x}<\mathrm{y}, \mathrm{x}>\mathrm{y}, \mathrm{x}=\mathrm{y}$. 
do menor. As perguntas seguintes, que dizem respeito a quem comeu mais bolo ou pizza, acabam por confirmar isso. Uma questão poderia ser colocada, então: se existem várias maneiras de se compararem maçãs, não existirão, também, várias maneiras de se compararem números?

Tendo em vista que esse discurso se constituiu numa perspectiva do Modelo dos Campos Semânticos (LINS, 1999), diremos que o aspecto central da cognição humana é a produção de significados, sendo o significado compreendido como aquilo que se pode dizer, e efetivamente se diz, sobre algo numa dada atividade. O que chama a atenção, nessa perspectiva, é que o conhecimento é do âmbito da enunciação. Dessa maneira, a comparação de números enquanto um texto matemático não é um conhecimento. Já quando a professora fala sobre as diferentes maneiras de se compararem duas maçãs está em jogo não somente a afirmação de que isso é verdade, mas, fundamentalmente, que isso é verdade para alguém, ou, ainda, para um determinado grupo ao qual se fala.

A situação acima ilustra que um conhecimento somente se constitui a partir de um par formado por crença-afirmação e justificação. A professora crê-afirma os diversos modos de comparar maçãs e justifica exibindo exemplos disso, como a comparação por cor, tamanho e textura. A justificação diz do porquê a professora entender sua crença-afirmação como legítima para o seu grupo de alunos. Dessa maneira, a justificação não procura explicar a crença-afirmação, mas produzir legitimidade para ela (LINS 1999, p. 88).

Ora, ao refazer a pergunta para seus alunos considerando a comparação entre 5 e 8 , somente a fala do primeiro aluno é considerada legítima pela professora. E as outras duas? Por que não o são?

Lins (1994) caracteriza um campo semântico como um modo de produção de significados. Numa reformulação posterior dessa noção, o autor vai vinculá-la com as noções de estipulação local, núcleo e atividade (LINS, 1999). As estipulações locais são entendidas como afirmações que são aceitas como verdadeiras sem justificativa. Um conjunto de estipulações é chamado de núcleo de uma atividade. A constituição de núcleos e estipulações se dá sempre no interior da atividade, não sendo possível defini-las a priori dos processos de produção de significado.

Voltemos ao caso da professora e de seus alunos. Do ponto de vista do Modelo dos Campos Semânticos, existem dois modos de produção de significados distintos na situação: um diz respeito à fala da professora em sua comparação entre maçãs, e outro que é inaugurado quando ela pergunta como se comparam dois números. Não é possível produzir significados para a comparação de números operando junto aos significados produzidos para se compararem frutas. Existe aí um limite epistemológico (LINS, 1993). Porém, como toda fala 
se quer legítima, os alunos explicitaram, de algum modo, três diferentes maneiras de comparar números. Haveria, assim, uma variedade de possibilidades de comparação entre números. A lógica da diversidade de comparações possíveis, que estava presente nos significados produzidos para comparar maçãs, não se constitui, porém, como parte dos significados para comparar números naquela aula, pois a professora não os legitima.

É preciso considerar o papel da professora como legitimadora ou não das enunciações dos alunos. Na sala de aula, as falas dos alunos se dirigem a ela. Muito embora fosse possível considerar como pertencentes ao conjunto de significados produzidos para comparar números qualquer uma das três afirmações, dependendo das justificativas utilizadas pelos alunos, isso acaba não acontecendo de fato.

$$
* * *
$$

Problematização: o que faremos aqui é problematizar, no sentido que já discutimos anteriormente, os dois discursos acerca do evento relatado da sala de aula de matemática. Procuraremos explicitar alguns efeitos presentes nos dois discursos apresentados. A questão poderia ser colocada da seguinte maneira: se assumo o discurso da Teoria dos Campos Conceituais ou do Modelo dos Campos Semânticos, o que vem junto? Que noções são constituintes dessas teorizações?

O discurso ligado à Teoria dos Campos Conceituais parte do pressuposto de que o pensamento humano se desenvolve de acordo com etapas previsíveis, estruturadas segundo o pensamento científico. Assim, ainda que o desenvolvimento cognitivo dependa da ação de um sujeito sobre o objeto, a construção fica submetida a estruturas mentais universais que são as próprias estruturas lógico-matemáticas. Gostaríamos de destacar dois conceitos.

O primeiro diz respeito à própria noção de estrutura mental proposta por Piaget que vai se manter na proposição da Teoria dos Campos Conceituais. Tomemos duas características da estrutura de que o autor fala. A totalidade é compreendida como a constituição de leis de composição interna que regem os elementos constituintes da estrutura e que acabam por conferir ao todo propriedades de conjuntos que, sozinhos, os elementos não necessariamente possuem. Já a autorregulação é pensada sob o duplo aspecto da conservação e fechamento das leis de transformação. Enquanto a totalidade vai levar Piaget a considerar que o pensamento funciona conforme leis de composição operatórias que se constituem enquanto sistema de transformações, a noção de autorregulação vai garantir a coerência interna do pensamento, já que tudo o que é construído por ele se submete às leis gerais que o estruturam, ou seja, o sistema de transformações não gera nada fora de si próprio. 
O segundo diz respeito à noção de teoremas-em-ação no âmbito da Teoria dos Campos Conceituais, que são entendidos como "competências práticas não explicitáveis simbolicamente" (LESSA; DA ROCHA FALCÃO, 2005, p. 316). Para cada teorema-em-ação corresponde um conceito-em-ação, que se relaciona ao saber formal que desencadeia o teorema-em-ação.

O que queremos chamar atenção é o fato de que, para Vergnaud, todas as situações enfrentadas pelo sujeito fazem referência, ainda que de maneira implícita, a um saber de referência dado de antemão pela matemática científica. Mais do que isso, a noção de estrutura acaba por garantir um desenvolvimento cognitivo que obedece a leis de composição interna e que concorre para um funcionamento invariante. Dessa maneira, o que ocorre é um fechamento à variação cognitiva. As etapas de desenvolvimento concorrem para um construtivismo de caminho necessário, o que acaba por deixar de fora o problema da invenção (KASTRUP, 2007). Nessa perspectiva, a aprendizagem matemática resta como uma construção sucessiva de representações para conceitos matemáticos científicos.

Esse fechamento ao problema da invenção, porém, é apenas teórico: os pressupostos da epistemologia genética produzem uma noção de cognição que investiga as condições de funcionamento da recognição. Mas a inventividade não pode ser apagada da sala de aula de matemática, já que o que acontece lá são relações de forças que inventam, a um só tempo, si e mundo A invenção fica como um resto não investigado pela Teoria dos Campos Conceituais, muito embora subsista como um problema político, como acontecimento na sala-de-aula-de-matemática.

Já o discurso que se liga ao Modelo dos Campos Semânticos toma como fundamento o pressuposto de Vigotski segundo o qual todas as funções intrapsicológicas já foram, em algum momento anterior, interpsicológicas (VIGOTSKI, 2009). A aprendizagem, portanto, é um processo de internalização das formas culturais de conhecer. No Modelo dos Campos Semânticos, o que se internalizam são modos de produção de significado, ou seja, o que se internalizam são os próprios campos semânticos (LINS, 1994).

Sancovschi (2005, p. 93) traz de Tudge a ideia segundo a qual a teoria psicológica de Vigotski traz em si uma teleologia que é a apropriação cultural. Para a autora, essa ideia de teleologia acaba por minar a originalidade dos conceitos vigotskianos (SANCOVSCHI, 2005, p. 94). Se a aprendizagem se configura como um processo de apropriação dos modos culturais de conhecer e significar objetos, operamos no campo da representação. Explico: concebida como produção humana sujeita às relações sociais, a matemática passa a se constituir como um ente cultural cujo conteúdo deve ser ensinado na escola. Passa-se, 
então, para a questão de que conteúdos vão para a sala de aula. Ora, vemos duas possibilidades: $1^{\text {a }}$ ) estabelecemos uma matemática que vai ganhar corpo nas salas de aula, constituindo-se hegemonicamente com relação às demais como uma imagem universal do pensamento que deve ser representada; $2^{a}$ ) dadas as diversidades culturais, tenta-se dar conta de diferentes contextos sociais em sala de aula, apropriando-se de diferentes modos de pensar e agir que coexistem socialmente. De qualquer maneira, ao operarmos um corte na matemática que chega à sala de aula, acaba-se fazendo uma espécie de congelamento em seu processo de produção, tomando pontos de estabilidade da cultura matemática como tópicos escolares. A cognição praticada aqui - ou, digamos, a política cognitiva que opera aqui é a da recognição, uma vez que agora as formas culturais de pensar e agir se configuram como as imagens de pensamento que a Educação Matemática tem por missão perpetuar. Isso tem por efeito a proliferação de Imagens de Pensamento que se desenvolvem de modo que encontrem ressonância com as variáveis culturais.

Dessa maneira, a aprendizagem resta como um processo de reconhecimento de imagens que agora operam no seio da cultura, ainda que tais imagens sejam mutáveis. Resiste, portanto, uma afinidade da aprendizagem com o conteúdo das imagens. No caso do Modelo dos Campos Semânticos, a internalização dos modos de produção de significado tem por efeito a constituição de falas que se querem legítimas para um interlocutor inserido no campo da cultura. Poderíamos dizer que, se não há nesse modelo, um construtivismo de caminho necessário, como na Teoria dos Campos Conceituais, em termos de estágios de desenvolvimento, o que há é uma construção teleológica cuja finalidade é a representação dos modos culturais de pensar e agir - imagens do pensamento no âmbito da cultura ${ }^{6}$.

Aqui cabe uma colocação importante. Ainda que a escola centre seus esforços na manutenção das formas culturais de agir e pensar, ainda que a manutenção dos conteúdos esteja fortemente presente, a cognição, por ser inventiva, produz escapes, bifurca, é violentada pela diferença. A questão que vai se delineando é, mais uma vez, ética: que matemática para que sala de aula? Colocados assim os termos, podemos problematizar as políticas cognitivas que se configuram na sala de aula de matemática, e não os discursos que procuram explicar ou legitimar determinados modos de pensar a partir de uma teoria.

\footnotetext{
${ }^{6}$ Uma problematização interessante que pode ser feita com relação ao Modelo dos Campos Semânticos diz respeito à noção de cultura que subjaz à psicologia vigotskiana. Sancovschi (2005) argumenta que entender a cultura de que fala Vigotski como algo em desenvolvimento acaba por enfraquecer a noção de télos cognitivo, o que poderia abrir brechas para pensar a invenção na interlocução com a psicologia histórico-cultural. Não entraremos nessa questão no presente texto.
} 


\section{O que pode a invenção?}

Para finalizarmos este texto, colocamos a seguinte questão: o que pode a cognição inventiva que já não podia a recognição em suas mais diversas perspectivas? Em particular, como ela pode nos ajudar a compreender a própria sala-de-aula-de-matemática? Talvez possamos apontar que a cognição inventiva nos ajude a construir, em sala de aula, um espaço de problematização das formas cognitivas constituídas. Se voltarmos à vivência de campo que narramos anteriormente, podemos apontar para dois movimentos de ruptura do fluxo cognitivo habitual.

O primeiro diz respeito à própria noção de comparação. A fala dos alunos, em especial aquele que compara os números por meio dos conceitos de par e ímpar, acaba por problematizar aquilo que o saber matemático formal diz sobre a comparação de números naturais. São produzidos modos de comparar naquele espaço que poderiam não estar em jogo se a configuração de forças que compõe aquela sala-de-aula fosse outra. A produção de uma matemática resiste ali: afinal, constitui-se um saber na comparação "8 é par e 5 é ímpar", ainda que isso não seja legitimado pela fala da professora.

O segundo diz respeito à discussão final da aula acerca da divisão do bolo em partes iguais. Ali se aponta uma discussão sobre um aspecto ético da divisão euclidiana. Todas as partes em que se divide um inteiro são necessariamente iguais. Porém, ao dizer que dá mais bolo para quem gosta mais, um dos alunos problematiza um dos pressupostos que fundam a operação de divisão por meio de uma força afetiva. A ideia de partilhamento que subjaz à divisão é colocada em questão. A matemática é problematizada e, ao dar corpo a um mundo, se constitui nela própria.

O conhecimento como invenção de sentidos abre-se para o movimento da vida-imanência, para os fluxos, para as experiências: não há uma imagem congelada da vida, mas um corte no caos que é uma busca na direção de olhar para as forças em seus movimentos, em seus entrelaçamentos, em suas lutas - aí a matemática deixa de ser o modelo e passa a ser parte dessa vida-imanência, participando da experiência, daquilo que nos atravessa, que nos passa, que nos acontece e se liga à vida como complexidade de forças em luta, à vida como imanência, como inusitabilidade, como emaranhado de experiências e atravessamentos (CLARETO, 2008, p. 10-11, grifo da autora).

A matemática que é produzida na sala-de-aula não se constitui fora da matemática canônica e dos saberes formais, tampouco os nega. Ao contrário, opera em seu interior por meio de um movimento de diferenciação e produz formas que não podem ser antecipadas, previstas. Nesse sentido, a cognição se configura como um movimento de invenção de problemas (KASTRUP, 2005). Além disso, tal relação de conhecimento produz um saber que não tende à universalidade, mas que possui uma diferença intrínseca que pode ser 
problematizada novamente, apontando para a repetição, no sentido dado por Deleuze (2006), do movimento de diferenciação. A recognição resta, aqui, como efeito provisório de estabilização, como um momento do processo cognitivo que guarda em si uma instabilidade. É nesse sentido que falar em processos inventivos na sala-de-aula-de-matemática não anula a legitimidade e possibilidade das leituras propostas pela Teoria dos Campos Conceituais e pelo Modelo dos Campos Semânticos. Ao contrário, afirma a singularidade e a potência de produção do modo de ler os processos cognitivos de cada uma, já que opera no âmbito do questionamento de seus efeitos e não no âmbito da vontade de verdade. Esse é um ponto chave a ser considerado: as políticas cognitivas que instauram modelos representacionais acabam por levar a cabo uma constituição moral e moralizante do conhecimento. Elas operam segundo uma vontade de verdade. Desse modo, fazer operar a invenção, cultivar uma política cognitiva que a leve em conta é colocar em questão essa vontade de verdade.

Uma Educação Matemática que sustente a sala-de-aula como espaço de problematização, de produção do sempre novo - eis o que pode a invenção: uma Educação Matemática atenta, que prima por uma atitude frente aos processos de conhecer, cultiva uma política cognitiva: invenção recíproca e indissociável de si-matemática.

\section{Referências}

CAMARGO, G. A. Sobre o conceito de verdade em Nietzsche. Revista Trágica: estudos sobre Nietzsche, Rio de Janeiro, v. 1, n. 2, p. 93-112, 2008.

CAMMAROTA, G. G.; SILVA, A. A.; CLARETO, S. M. O plano coletivo de forças como potência de invenção de uma sala-de-aula-de-matemática. In: CLARETO, S. M.; ROTONDO, M. A. S.; VEIGA, A. L. V. S. da (Orgs.). Entre composições: formação, corpo e educação. Juiz de Fora: Editora UFJF, 2011. p. 101-117.

CLARETO, S. M. Educação Matemática e inventividade: na busca de agenciamentos. In: COLÓQUIO FRANCO-BRASILEIRO DE FILOSOFIA DA EDUCAÇÃO: filosofia, aprendizagem, experiência, 4., 2008. Anais... Rio de Janeiro: UERJ, 2008.

DELEUZE, G. Diferença e repetição. Rio de Janeiro: Graal, 2006.

DELEUZE, G.; GUATTARI, F. Mil Platôs. São Paulo: Editora 34, 1997. v. 5.

KASTRUP, V. Políticas cognitivas na formação do professor e o problema do devir-mestre. Educação \& Sociedade, Campinas, v. 26, n. 93, p. 1273-1288, set./dez. 2005. DOI: 10.1590/ S0101-73302005000400010

A invenção de si e do mundo: uma introdução do tempo e do coletivo no estudo da cognição. Belo Horizonte: Autêntica, 2007.

O funcionamento da atenção no trabalho do cartógrafo. In: PASSOS, E.; KASTRUP,

V.; ESCÓSSIA, L. (Orgs.). Pistas do método da cartografia: pesquisa-intervenção e produção de subjetividade. Porto Alegre: Sulina, 2009. p. 32-51. 
KASTRUP, V.; TEDESCO, S.; PASSOS, E. Políticas da cognição. Porto Alegre: Sulina, 2008.

LESSA, M. M. L.; DA ROCHA FALCÃO, J. T. Pensamento e linguagem: uma discussão no campo da Psicologia da Educação Matemática. Psicologia: reflexão e crítica, Porto Alegre, v. 18, n. 3, p. 315-322, 2005. DOI: 10.1590/S0102-79722005000300004

LINS, R. C. Epistemologia, história e Educação Matemática: tornando mais sólidas as bases de pesquisa. Revista da SBEM - SP, Campinas, v. 1, n. 1, p. 75-91, 1993.

O modelo teórico dos campos semânticos: uma análise epistemológica da álgebra e do pensamento algébrico. Dynamis, Blumenau, v. 1, p. 29-39, abr./jun. 1994.

. Por que discutir teoria do conhecimento é relevante para a Educação Matemática. In: BICUdO, M. A. V. (Org.). Pesquisa em Educação Matemática: concepções e perspectivas. São Paulo: Editora da UNESP, 1999. p. 75-94.

NIETZSCHE, F. Além do bem e do mal: prelúdio a uma filosofia do futuro. Tradução de Paulo César de Souza. São Paulo: Companhia das Letras, 1992.

A gaia ciência. Tradução de Paulo César de Souza. São Paulo: Companhia das Letras, 2001a.

Genealogia da moral: uma polêmica. Tradução de Paulo César de Souza. São Paulo: Companhia das Letras, 2001b.

PASSOS, E.; EIRADO, A. cartografia como dissolução do ponto de vista do observador. In: PASSOS, E.; KASTRUP, V.; ESCÓSSIA, L. (Orgs.). Pistas do método da cartografia: pesquisa-intervenção e produção de subjetividade. Porto Alegre: Sulina, 2009. p. 109-130.

PASSOS, E.; KASTRUP, V.; ESCÓSSIA, L. (Orgs.). Pistas do método da cartografia: pesquisa-intervenção e produção de subjetividade. Porto Alegre: Sulina, 2009.

PIAGET, J. O estruturalismo. Rio de Janeiro: Difusão Editorial, 1979.

SANCOVSCHI, B. Sobre a aprendizagem: ressonâncias entre a abordagem enativa de F. Varela e a psicologia histórico-cultural de L. S. Vygotski. 2005. 143 f. Dissertação (Mestrado em Psicologia) - Instituto de Psicologia, Universidade Federal do Rio de Janeiro, Rio de Janeiro, 2005.

SANTOS PRATA, M. R. A produção de subjetividade e as relações de poder na escola: uma reflexão sobre a sociedade disciplinar na configuração social da atualidade. Revista Brasileira de Educação, Rio de Janeiro, n. 28, jan./abr. 2005. DOI: 10.1590/S141324782005000100009

VARELA, F. Conhecer: as ciências cognitivas, tendências e perspectivas. Lisboa: Instituto Piaget, [199-].

VERGNAUD, G. Psicologia cognitiva y del desarrollo y didacticas de las matemáticas. In. HUARTE, F. Temas actuales sobre psicopedagogia y didactica. Madrid. Espanha, 1988.

VIGOTSKI, L. S. A construção do pensamento e da linguagem. São Paulo: Martins Fontes, 2009.

Recebido em 19/03/2012

Aceito em 10/10/2012 